\title{
ESTEBAN TORRE: Visión de la realidad y relativismo posmoder- no. (Perspectiva teórico-literaria). Madrid: Arco/Libros, 2010.
}

Hay algunos autores que tienen la rara capacidad de intuir de qué cosa es necesario hablar y sobre qué se puede hacer un estudio interesante. El profesor Esteban Torre, doctor en Medicina y Cirugía y en Filosofía y Letras, y Catedrático Emérito de Teoría de la Literatura y Literatura Comparada en la Universidad de Sevilla, pertenece a ese grupo de escogidos que son capaces de simplificar - de aclarar- los temas más complejos. Cuando los estudios métricos parecían estancarse como consecuencia, precisamente, del relativismo posmoderno, Esteban Torre publicó su Métrica española comparada que daba cuenta de la naturaleza del verso español, incluyéndolo en el sistema mayor de las lenguas europeas. Del mismo modo, restaba libertad a todos aquellos que hablaban demasiado apresuradamente del verso libre.

Visión de la realidad y relativismo posmoderno. (Perspectiva teórico-literaria) se publica este año, en la Colección Perspectivas, de la editorial Arco/Libros, para que el lector interesado sea capaz de comprender mejor qué es la posmodernidad y cómo nace su característica principal: el relativismo. Al mismo tiempo, la Teoría de la Literatura, y los estudios métricos, son utilizados por el autor para defender el absolutismo de los valores eternos del arte, y sirven como contrapunto a la perspectiva relativista del pensamiento posmoderno.

La virtud dellibro radica en el hecho de que el profesor Torre acude directamente a las fuentes de la posmodernidad para llevar a cabo un análisis pormenorizado y riguroso de las aportaciones de los filósofos, historiadores y teóricos de la ciencia más influyente del pasado siglo: el método hipotético-deductivo de Karl Popper, la teoría de los paradigmas de Thomas Kuhn y el anarquismo metodológico de Paul Feyerabend. Tras estos autores, que sientan las bases de la nueva manera de relacionarse con la realidad y de entender el objetivo último de la ciencia, entran en escena las teorías de todos aquellos epígonos que presentan ya, abiertamente, una postura relativista frente al mundo. Esteban Torre detalla los as- 
pectos más destacables del relativismo nihilista, teoría del filósofo estadounidense de la ciencia Richard Rorty, que abandona definitivamente la preocupación por el hallazgo de la verdad y, frente a la oposición real/aparente, pretende instituir la distinción útil/inútil.

Esas teorías iniciales se transforman, influidas tal vez por la crisis de valores de la sociedad contemporánea, en pretextos para la elaboración de sistemas de conocimiento que desvirtúan el espíritu y la intención de aquellos teóricos. La mirada irónica del autor se enfrenta a esa tradición científica donde lo profundo debe ser oscuro y desvela las imposturas y las mistificaciones de algunos autores de prestigio (es éste, quizá, el capítulo del libro más crítico con la superchería pseudocientífica de la posmodernidad). Esteban Torre reduce a sus justos límites la verdad científica que se oculta tras los términos -con enunciados ciertamente aprovechables por los filósofos relativistas- que provienen de ciertas ciencias experimentales, como la Física o las Matemáticas. Así, la teoría de la relatividad de Einstein, la teoría del caos de Lorenz, el teorema de la incompletitud o de la indecidibilidad de Gödel o el principio de incertidumbre o de indeterminación de Heisenberg son utilizados como ejemplos de la imposibilidad del conocimiento científico, si bien la teoría del caos, por ejemplo, según señala Lorenz, citado por el autor, no es más que "un comportamiento aleatorio e impredecible que, pese a ello ocurre de acuerdo con reglas precisas y, a menudo, fácilmente formulables". En el recorrido por esas imposturas y mistificaciones, tiene especial relieve la atención prestada a la "broma científica" del físico norteamericano Alan Sokal, que muestra, a través de la parodia y con alta dosis de humorismo, los grandes defectos de las teorías relativistas.

Frente al sistema de falsedades instituido por algunos teóricos posmodernos, el autor del libro defiende la importancia de la Estética y de los valores artísticos, por encima de modas y de épocas. En el capítulo 4, se atiende al estado en que se encuentra el concepto de arte (aplicado a la pintura, la escultura, la literatura...) en "el abismo de la posmodernidad". Se analiza aquí la dificultad de distinguir aquello que puede considerarse artístico y aquello que no reúne las condiciones para ser arte. Son varias las teorías analizadas en el libro en las que el arte absoluto y real se sustituye por una vaga creencia en las situaciones y en el poder institucional: la teoría de Goodman, quien aboga por la sustitución de la pregunta ¿qué es el arte? por la pregunta ¿cuándo es arte?, más fructífera, según él, que la anterior; o la teoría institucional de George Dickie, 
que sostiene que no es arte lo que posee una serie de valores artísticos sino aquello que las instituciones determinan conforme a unos cánones preestablecidos.

La discusión teórica sobre la posmodernidad se completa con un sólido estudio de la métrica y de los principios de la poesía. En el capítulo cuarto, Esteban Torre demuestra claramente que ha de eliminarse el relativismo existente en el juicio de las artes, aplicando a la literatura los métodos objetivos de la ciencia del verso. E1 autor del libro entiende que algo es un verso cuando cumple una serie de características métricas y, cuando no es así, aunque se pretenda, el resultado no será un verso. Del mismo modo, en la poesía, por definición, no cabe la mediocridad y, por tanto, no existe la mala poesía, puesto que "si es mala, no es poesía". El verso, por consiguiente, se convierte en un instrumento determinante y muy útil para descubrir dónde se encuentra la poesía, qué es, verdaderamente, poesía. Esteban Torre lo define como "la unidad rítmica fundamental del conjunto poemático, y las sílabas y los acentos son los elementos básicos del metro, y constituyen el armazón rítmico del verso". El verso español se constituye como verso según la distribución de las sílabas tónicas y átonas y según el número de sílabas que lo componen. Para una correcta descripción del verso y una adecuada comprensión del sistema métrico español se debe prestar atención al acento y acometer siempre un preciso cómputo silábico. Para ello, según sostiene el autor, el dominio de ciertos aspectos problemáticos de la escansión métrica es imprescindible: la elisión y el encuentro de vocales, el concepto de verso simple y verso compuesto, y la terminación aguda, llana o esdrújula del verso.

La compleja terminología y numerosas matizaciones en torno al problema de la elisión y el encuentro de vocales podría subsanarse y simplificarse mediante la sencilla división que propone Esteban Torre: diptongo, si las vocales forman una sola sílaba, e hiato, si las vocales constituyen dos sílabas distintas.

Por otra parte, el verso compuesto no es más que la unión, en una sola línea, de dos versos simples, si bien estos versos simples suelen recibir la denominación de "medios versos" (hemistiquios) y la parada entre ellos, equivalente a la pausa final de un verso simple, cesura. El comportamiento, por lo tanto, de un verso compuesto es idéntico al de dos versos simples, aunque están colocados uno a continuación del otro, en una misma línea.

Por último, la terminación de un verso en palabra aguda, llana o 
esdrújula no es una cuestión esencial en la teoría métrica del autor porque, "en virtud de la pausa, la última sílaba acentuada del verso adquiere un carácter culminante, ya que el verso termina realmente en esta sílaba". Si en español se cuenta la sílaba postónica, es sólo por una cuestión que depende de la tradición, que fija como modelo el verso que acaba en palabra llana y que, por consiguiente, obliga a sumar una sílaba, si termina en palabra aguda, y a restar una sílaba, si termina en palabra esdrújula, en el cómputo silábico. Igualmente, la denominación del verso se establece, convencionalmente, a partir del verso que termina en palabra llana.

La métrica es un instrumento necesario para descubrir la verdadera poesía y desechar los intentos fallidos de los escritores. Sin embargo, no es fácil señalar dónde se encuentra la verdadera poesía, cuáles son esos valores que, pese a las afirmaciones de autores como Goodman o Dickie, se mantienen permanentemente. Aunque sea difícil precisarlos, no debe ser esto una excusa para no intentar, siquiera, aproximarse a la verdad estética e intelectual. Por esa razón, la segunda mitad de Visión de la realidad y relativismo posmoderno (Perspectiva teórico-literaria) está dedicada a mostrar el significado, y el valor literario, de algunos poemas de Quevedo y a hablar de la importancia de la traducción para que esos valores -que existen- no desaparezcan con la lengua original.

En el intento de que los valores literarios y estéticos -que existen- permanezcan en la traducción y puedan ser percibidos por el lector que no conoce la lengua original de los poetas, el profesor Torre elabora en este libro un interesante tratado métrico que completa el prólogo a su lograda traducción de algunas de las composiciones de los mejores autores grecolatinos, publicado en 1998, y reimpreso en 2001, por la Universidad de Huelva y el Consejo Superior de Investigaciones Científicas: La poesía de Grecia y Roma: ejemplos y modelos de la cultura literaria moderna. Se encuentra en este capítulo una teoría sobre la traducción de los versos clásicos de manera que, sin perder el sentido y el tono del original griego y latino, se pueda disfrutar de poemas cuya métrica no sea ajena a la versificación española; es decir, se plantea una traducción donde se emplea el verso de ritmo endecasilábico (desde el pentasílabo adónico hasta los versos compuestos por endecasílabos y eneasílabos, pasando, por supuesto, por el alejandrino), muy alejada esta manera de traducir, por tanto, de los ensayos fallidos de adaptar las sílabas largas y breves grecolatinas a las sílabas tónicas y átonas de la lengua española. 
Naturalmente, en la traducción del verso deben respetarse, también, las figuras retóricas que todo buen traductor descubre en el original. Como muestra sirva el ejemplo del hexámetro 596 del libro VIII de la Eneida, que el autor rescata de su traducción: quadripedante putrem sonitu quatit ungula campum. El profesor Torre mantiene "el estruendoso galopar de los caballos", que sugiere Virgilio, en el verso español, compuesto por un endecasílabo y un heptasílabo: "con trepidante galopar golpean el polvoriento campo".

Esteban Torre, siguiendo el dictado de Machado, sale, en este libro, a buscar la verdad -intelectual y estética- aunque para ello tenga que enfrentarse, incluso, a filósofos ya institucionalizados. Cualquiera menos honesto científicamente habría disimulado su incapacidad para descifrar la siguiente cita con otras citas, también indescifrables: "La diferencia no es lo diverso. Lo diverso es dado. Pero la diferencia es aquello por lo que lo dado es dado. Es aquello por lo que lo dado es dado como diverso". El profesor Torre - doctor en Medicina y Cirugía y en Filosofía y Letras, y Catedrático Emérito de Teoría de la Literatura y Literatura Comparada en la Universidad de Sevilla-, en cambio, propone un "curioso ejercicio": sustituir la diferencia por el pan, lo diverso por la harina, y lo dado por el trigo. El resultado es el siguiente: "El pan no es la harina. La harina es trigo. Pero el pan es aquello por lo que el trigo es trigo. Es aquello por lo que el trigo es trigo como harina". Efectivamente, este curioso ejercicio sirve para demostrar que, a veces, lo oscuro no es profundo, sino simplemente falso, y que lo claro aspira a aproximarse a la Verdad.

José Manuel Begines Hormigo 